\title{
Stress Properties Optimization of a Composite Sandwich Structure by Application of Hybrid Taguchi-GRA-PCA
}

\author{
Anil Kumar*, Surjit Angra** and Arindam Kumar Chanda*** \\ *Department of Mechanical \& Automation Engineering, GBPEC, New Delhi, India. \\ **Department of Mechanical Engineering, NIT, Kurukshetra, India. \\ Corresponding Author: anilapmae@gmail.com
}

\begin{abstract}
A sandwich structure is always designed to have maximum Strength and Stiffness. In this research, three main design factors i.e. facesheet thickness, core height and panel with each having three different values (levels) have been chosen and a L9 Orthogonal Array has been generated using Taguchi Design in Minitab software. The Sheet Stresses and Shear Stresses have been calculated for all 9 configurations. From Taguchi Analysis it has been observed that the optimum level for different design parameters are F/S thickness $.8 \mathrm{~mm}$, Core Height $8 \mathrm{~mm}$ and Panel Width $50 \mathrm{~mm}$.Then PCA assisted GRA has been performed on the two responses and it has been observed that the optimum parameter level are F/S thickness. 8mm, Core Height $8 \mathrm{~mm}$ and Panel Width 50mm. ANOVA analysis has also been performed to find out the effect of selected design elements on the two types of stress values of the sandwich panel. It has been observed that the Facesheet Thickness has the maximum effect on Sandwich Stresses.
\end{abstract}

Keywords:Kevlar® honeycomb core; FEA of composite sandwich structure; Taguchi analysis; PCA assisted GRA; ANOVA analysis

\section{INTRODUCTION}

Composite sandwich structures are fabricated by joining two or more different constituents with an adhesive for absorbing their properties. They have wide usage in automotive and space industry because they offer lots of advantages over other materials such as high strength, high stiffness, low density, low wear and high corrosion resistance. [1].Figure 1 shows the structure of a composite sandwich structure. 


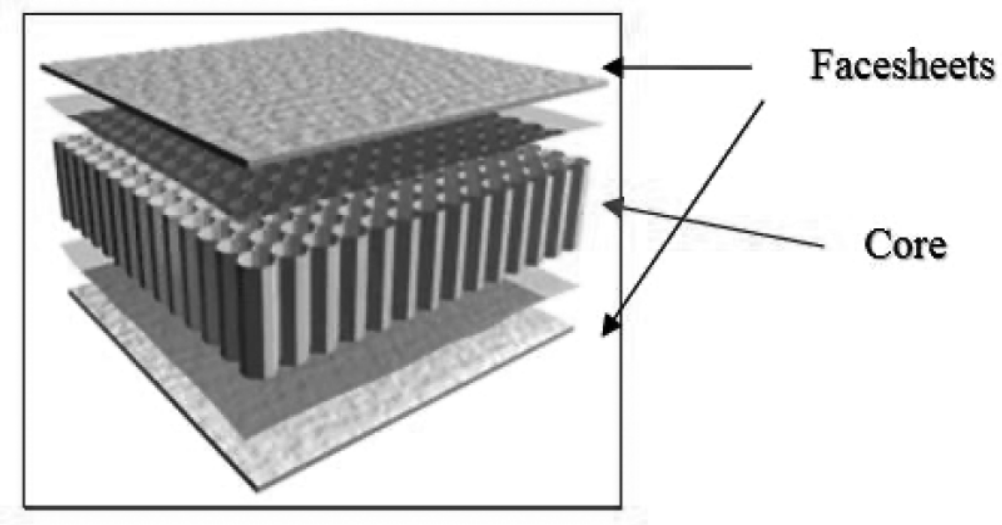

Figure 1. Sandwich Panel

Different studies have been conducted on the different types of behaviour of composite sandwich structures. Suresh Kumar et al. [3] observed that cell size along with core height is the most influencing structural parameters and the cell wall thickness is the least influencing one. Rupani et al. [4] observed that in $\mathrm{T}$ direction of core more compressive strength can be achieved and the Modelling of honeycomb sandwich structures with actual cell configuration is difficult and time consuming and it can be simplified by using equivalent homogeneous body for the core.

Altan et al. [5] suggested the method of detection of in-plane and out-of-plane effective elastic constants of honeycomb core. Kumar et al. [6] observed that by enhancing the height of core both tensile and flexural strength can be increased. Prakash et al. [7] found that the core shear modulus of PUR FOAM is pretty less than that FRP honeycomb core even if they have the same density.

Nurashikin et al. [8] in their experimental result observed that Al 6061 have the highest value of stress and force for both testing while thermoplastic shows the lowest value. Thomas et al. [9] observed that the most of the properties of a Honeycomb core depend on the different geometrical parameters like core cell size, core cell wall thickness etc.

Rao et al. [10] found that instead of core height, the wall thickness of a core cell is more responsible for determining the crushing strength of the sandwich panels. Akiwate et al. [11] also studied the effects of the variation in core height and sandwich panel skin to determine various mechanical properties.

Kumar et al. [12] observed that the stiffness value initially increases at a faster rate and then reduces and tends to become constant with increasing thickness of face sheet. Mohammed et al. [13] found that the honeycomb core having square shape bears the highest load as compared to other form of core shapes (hexagonal have the lowest value).

Form the literature review it has been observed that most of the research has been done on analysis of effect on properties of sandwich structure due to variation in core materials and core cell wall thickness, but not much research has been available on effects on sandwich stress properties due to variation of thickness of facesheet, height of commercial hexagonal honeycomb core and panel width of sandwich structure assisted with Taguchi design, Analysis and PCA-GRA. So, here seems an opportunity to make an analysis of variation of facesheet, height of commercial hexagonal honeycomb core and panel width of sandwich structure assisted with Taguchi design, Analysis and PCA-GRA.

In this research, three main design factors i.e. facesheet thickness, core height and panel with each having three different values (levels) will be chosen and a L9 Orthogonal Array will be generated using Taguchi Design in Minitab software. Then, as per the fifth configuration given by Taguchi Design, a sandwich structure will be modelled and FEA of this modelled structure (three point bending test) will be 
done in ANSYS. From FEA the Critical load and ultimately the deflection in the panel will be calculated. After that a sandwich structure having the similar configuration to that of the initially modelled configuration will be fabricated and it also will be tested for Three Point Bending Test on UTM as per ASTM 393 standard. The deflection obtained through two different testing methods for sandwich panel will be compared and validation of the model will be checked. After generating a valid sandwich panel model, the critical load values using FEA will be calculated for all nine configurations and ultimately the Sheet stress and Shear stress in the sandwich panel can be detected. Then these values of sheet stress and shear stress will be entered in the L9 OA as responses and Taguchi analysis will be performed. Using Taguchi analysis the optimum parameter levels will be obtained. Then PCA assisted GRA will be performed on the two responses again the optimum level for different parameter will be obtained. Then confirmatory test and ANOVA analysis will also be performed to determine the effect of different design parameters on the different stress values of the sandwich panel.

\section{EXPERIMENTAL WORK}

\subsection{Selection Of Raw Material and Different Design Parameters For Sandwich Structure-}

\section{a. Material Selection-}

The following materials has been selected for the different elements of the sandwich structure-

1. Face Sheet Material- Carbon fiber (It will be responsible for bearing the bending stress of the sandwich structure. Carbon fibers have higher elastic constants, so they act as best material for facesheet.)

2. Core Material- Kevlar Honeycomb core (It is made up of Kevlar fibers which are Para -Aramid fibers. (PK2 Plascore) [2] Kevlar Honeycomb Structure has High tensile strength and High tensile modulus Also Kevlar is about five times lighter than steel in terms of the same tensile strength.

3. Adhesive -Epoxy with Hardener (18\%).

\section{Design Parameters-}

The main design parameters chosen for composite sandwich structures are -

$\begin{array}{ll}\text { 만 } & \text { Core Thickness- }(8 \mathrm{~mm}, 10 \mathrm{~mm} \text { and } 12.7 \mathrm{~mm}) \\ \text { ㅁ } & \text { Face sheet Thickness- }(.4 \mathrm{~mm} .6 \mathrm{~mm} \text { and } .8 \mathrm{~mm}) \\ \text { ㅁ Panel Width - }(40 \mathrm{~mm}, 45 \mathrm{~mm}, 50 \mathrm{~mm})\end{array}$

\subsection{Taguchi Design}

Due to its suitability, Taguchi Design has been adopted and for this, 3 factors with each having 3 levels have been utilized. These factors have been entered in Minitab 19 software and the following L9 OA has been received as shown in table 1 below. 
Table1. L9 OA obtained through Taguchi Design

\begin{tabular}{|c|c|c|c|}
\hline Configuration No. & FST & CH & PW \\
\hline 1 & 0.4 & 8.0 & 40 \\
\hline 2 & 0.4 & 10.0 & 45 \\
\hline 3 & 0.4 & 12.7 & 50 \\
\hline 4 & 0.6 & 8.0 & 45 \\
\hline 5 & 0.6 & 10.0 & 50 \\
\hline 6 & 0.6 & 12.7 & 40 \\
\hline 7 & 0.8 & 8.0 & 50 \\
\hline 8 & 0.8 & 10.0 & 40 \\
\hline 9 & 0.8 & 12.7 & 45 \\
\hline
\end{tabular}

\subsection{Modelling And Finite Element Analysis}

Modelling is done in the Ansys as shown in figure 2. The Face sheets are modelled orthotopically in the Ansys composite prep-post while the homogenised core is modelled in Design modeller available in Ansys. The homogenised core is modelled by replacing honeycomb cells with a solid core as shown in figure 3 .

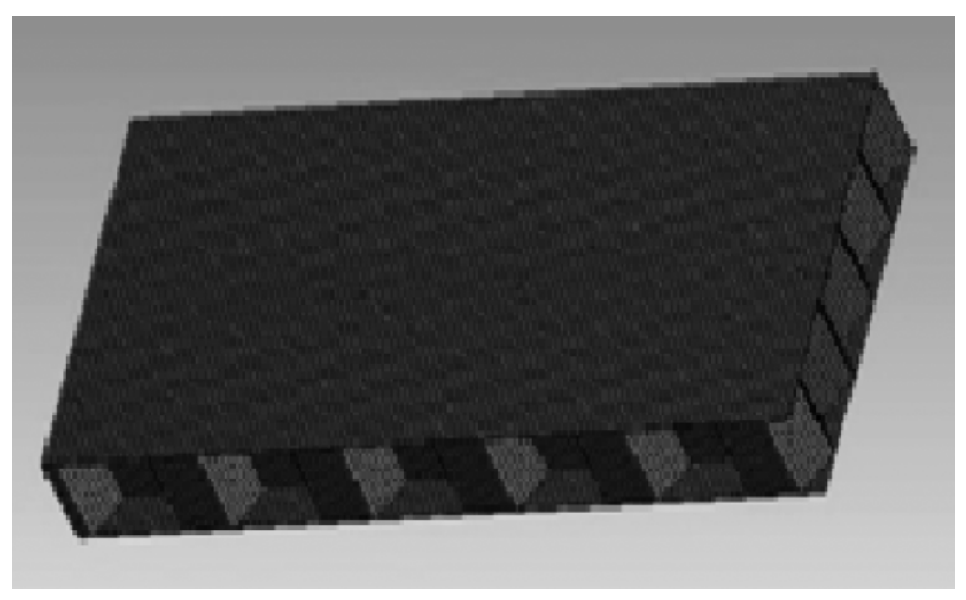

Figure 2. Modelling with actual honeycomb 


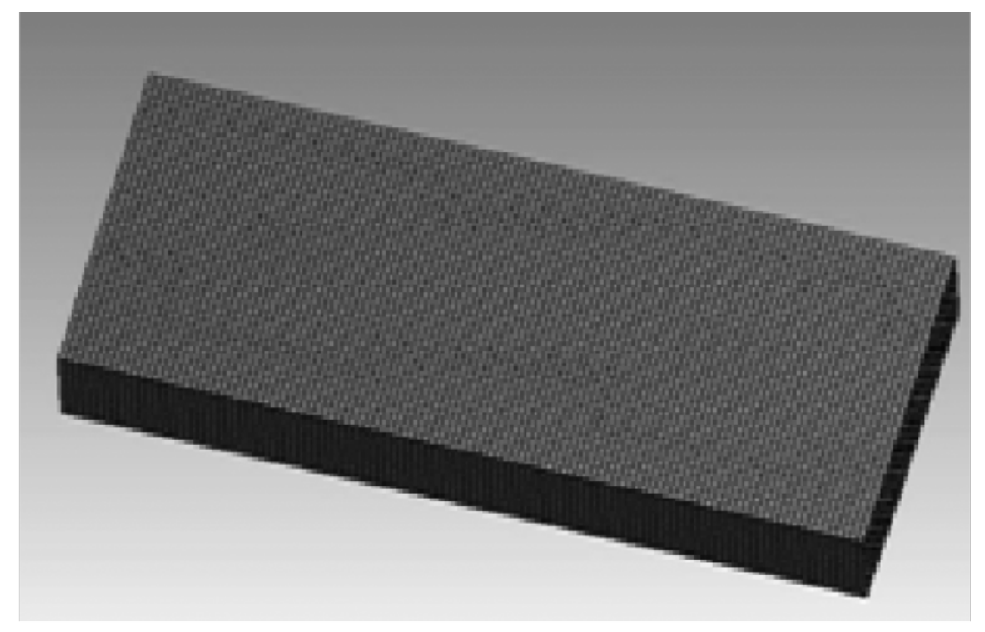

Figure 3. Equivalent modelling

For the Validation of Model, the Central Configuration form Taguchi L9 OA i.e. the 5th Configuration, as shown in Table 1 has been selected for Finite Element and Experimental Analysis.

For FEA, it has been assumed that sandwich will fail due to shearing of the core.

\section{Finite Element Analysis of Configuration 5-}

a. Critical Load obtained by FEA for configuration 5-

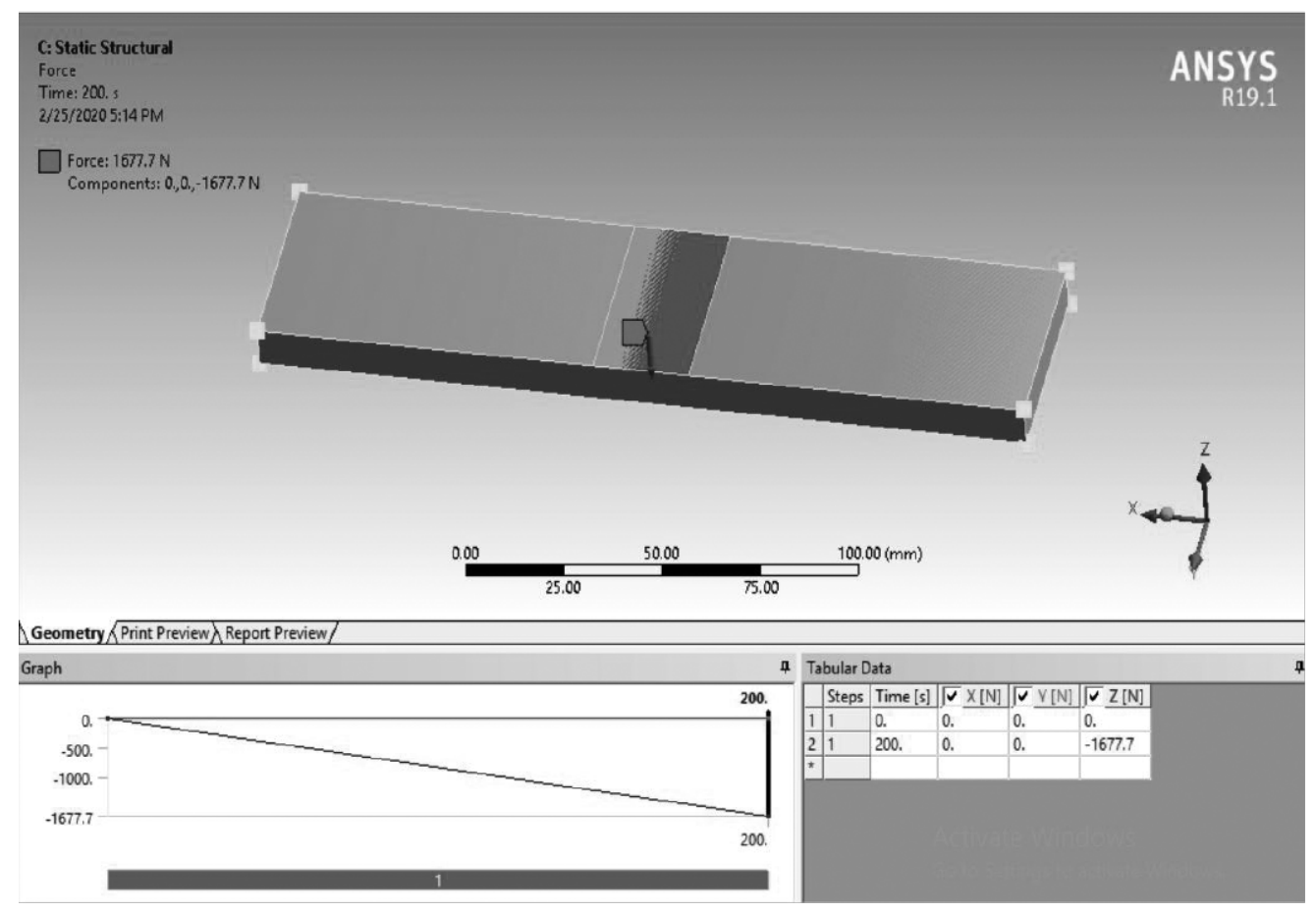

Figure 4. FEA for obtaining the Critical Load for configuration 5 
Figure 4 shows that the value of critical load obtained by FEA of the configuration no. 5 is $1677.7 \mathrm{~N}$.

b. Panel Deflection obtained by FEA for configuration 5-

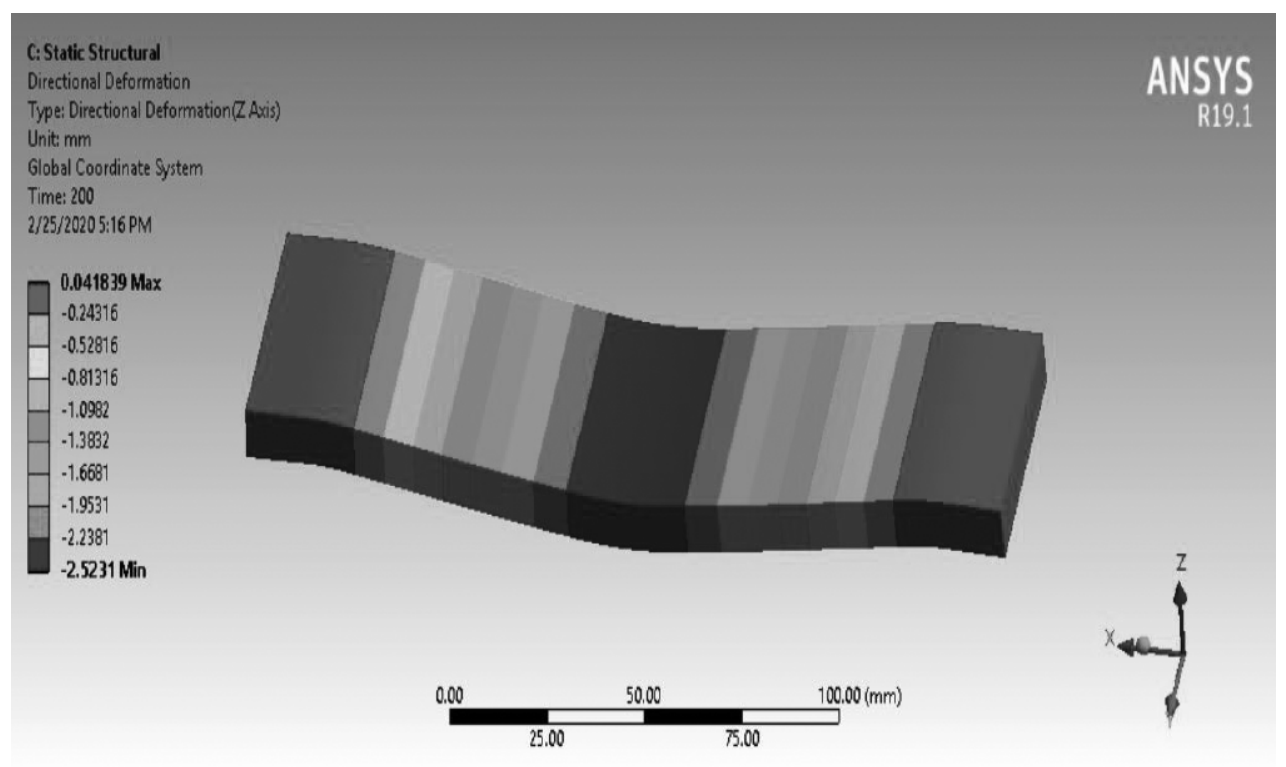

Figure 5. FEA for obtaining the Deflection for configuration 5

Figure 5 shows that the value of critical load obtained by FEA of the configuration no. 5 is $2.253 \mathrm{~mm}$.

\subsection{Experimental Analysis For Composite Sandwich Panel}

The sandwich structure having the configuration similar to the Fifth configuration as that of the Taguchi Design has been produced using the "Vacuum Assisted Hand Lay-Up Method". The figure 6 shows the finally fabricated sandwich panel.

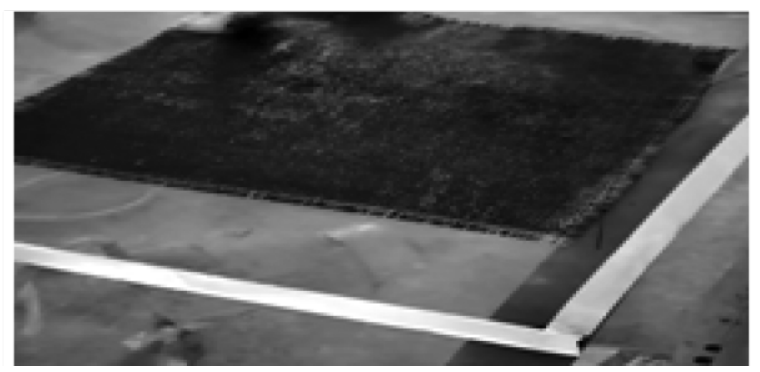

Figure 6. Finally Fabricated Sandwich Panel

Then three point Bend Test has been performed on a sandwich panel having span length $150 \mathrm{~mm}$ and width $50 \mathrm{~mm}$ as per ASTM C393 standard and the values of critical load has been calculated and ultimately the deformation in panel has been detected. Figure 7 shows the tested specimen. 


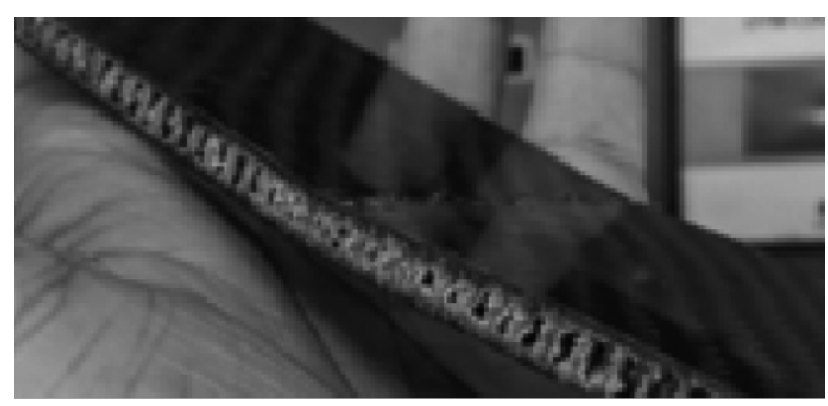

Figure 7. A Test Specimen after 3-Ponit Bend Test

The value of critical load calculated for this test is $1660 \mathrm{~N}$. Using the following formulae, the different properties of sandwich panel can be obtained-

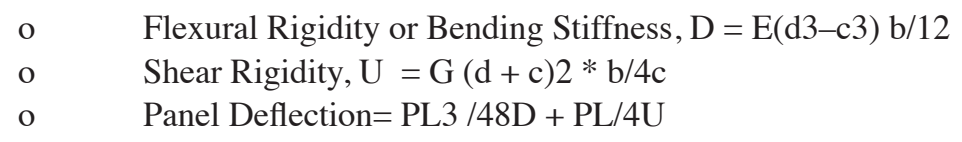

Where, Core thickness (c),

Face-sheet thickness (t),

Sandwich Width (b),

Span length (L),

Critical force $(\mathrm{P})$,

Young's modulus (E) of face sheet (61340 MPA) and

Shear modulus (G) of core (98-102 MPA) are different notations.

Using the equations 1,2,3 and different corresponding values for chosen sandwich structure, the values obtained for $\mathrm{D}, \mathrm{U}$ and Deformation as $103.49 \mathrm{MNmm} 2,55056.40 \mathrm{~N}$ and $2.283 \mathrm{~mm}$ respectively.

\subsection{Fea Model Validation}

Table 5 shows the comparison in the results of the Load/Deflection obtained through FEA method and Experimental analysis. The percentage error between two types of analysis is within permissible range i.e. $1.16 \%$ so it has been achieved that the Model created is valid and this model can be utilized for analysis of similar type of composite sandwich structures.

Table 5. Result comparison of FEA and Experimental Analysis

\begin{tabular}{|c|c|c|c|}
\hline RESPONSE & FEA RESULTS & EXPERIMENTAL RESULTS & \% ERROR \\
\hline Stiffness & $380.29 \mathrm{~N} / \mathrm{mm}$ & 375.87 & $1.16 \%$ \\
\hline
\end{tabular}

\subsection{Taguchi Analysis For L9 Oa}

FEA model has been used for finding the ultimate load and ultimately the values of the two types of stress and then these all stress values have been tabulated as shown below. 
Table 6. Taguchi L9 OA with two types of Stress responses

\begin{tabular}{|c|c|c|c|c|c|}
\hline $\begin{array}{l}\text { S. } \\
\text { N. }\end{array}$ & $\begin{array}{l}\text { FST } \\
(\mathrm{mm})\end{array}$ & $\begin{array}{c}\mathbf{C H} \\
(\mathrm{mm})\end{array}$ & $\begin{array}{l}\text { PW } \\
(\mathrm{mm})\end{array}$ & $\begin{array}{c}\text { SHEET STRESS } \\
(\mathbf{N} / \mathbf{m m} 2)\end{array}$ & $\begin{array}{c}\text { SHEAR STRESS } \\
(\mathbf{N} / \mathbf{m m} \mathbf{2})\end{array}$ \\
\hline 1 & 0.4 & 8.0 & 40 & 2291.25 & 3.063 \\
\hline 2 & 0.4 & 10.0 & 45 & 2286 & 3.053 \\
\hline 3 & 0.4 & 12.7 & 50 & 2257.335 & 3.0125 \\
\hline 4 & 0.6 & 8.0 & 45 & 1472.625 & 2.959 \\
\hline 5 & 0.6 & 10.0 & 50 & 1493.145 & 2.995 \\
\hline 6 & 0.6 & 12.7 & 40 & 1505.378 & 3.017 \\
\hline 7 & 0.8 & 8.0 & 50 & 1081.605 & 2.908 \\
\hline 8 & 0.8 & 10.0 & 40 & 1104.353 & 2.961 \\
\hline 9 & 0.8 & 12.7 & 45 & 1119.593 & 2.996 \\
\hline
\end{tabular}

The Taguchi method employs a statistical tool of performance known as "Signal To Noise Ratio" denoted as $\mathrm{S} / \mathrm{N}$ ratio for the analysis of the responses. In this analysis, two response characteristics i.e. Sheet Stress and Shear Stress both are of "Smaller-is-better" type.

Taguchi Analysis for Sheet Stress and Shear Stress for "Smaller-is-better option" - Figure 5 and Figure 6 show "Main effects plot for Mean S/N ratios" for Sheet Stress and Shear Stress.

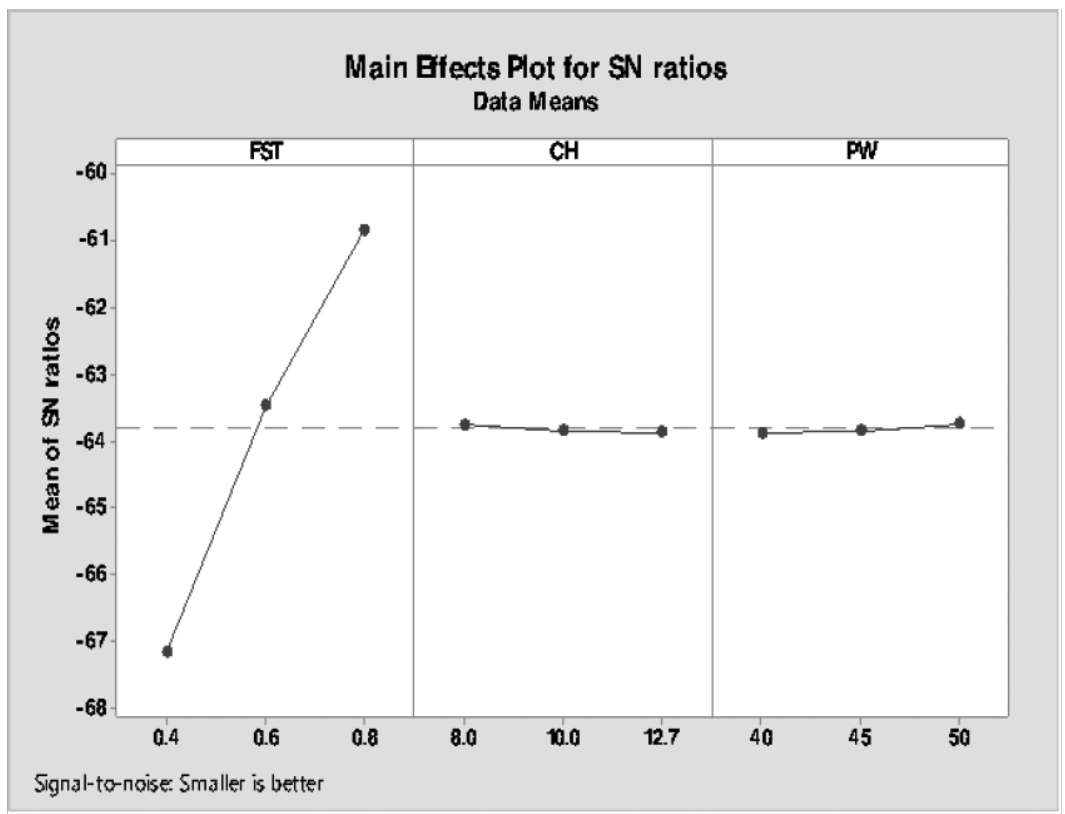

Figure 5. Main effects plot for SN ratios for Sheet Stress 


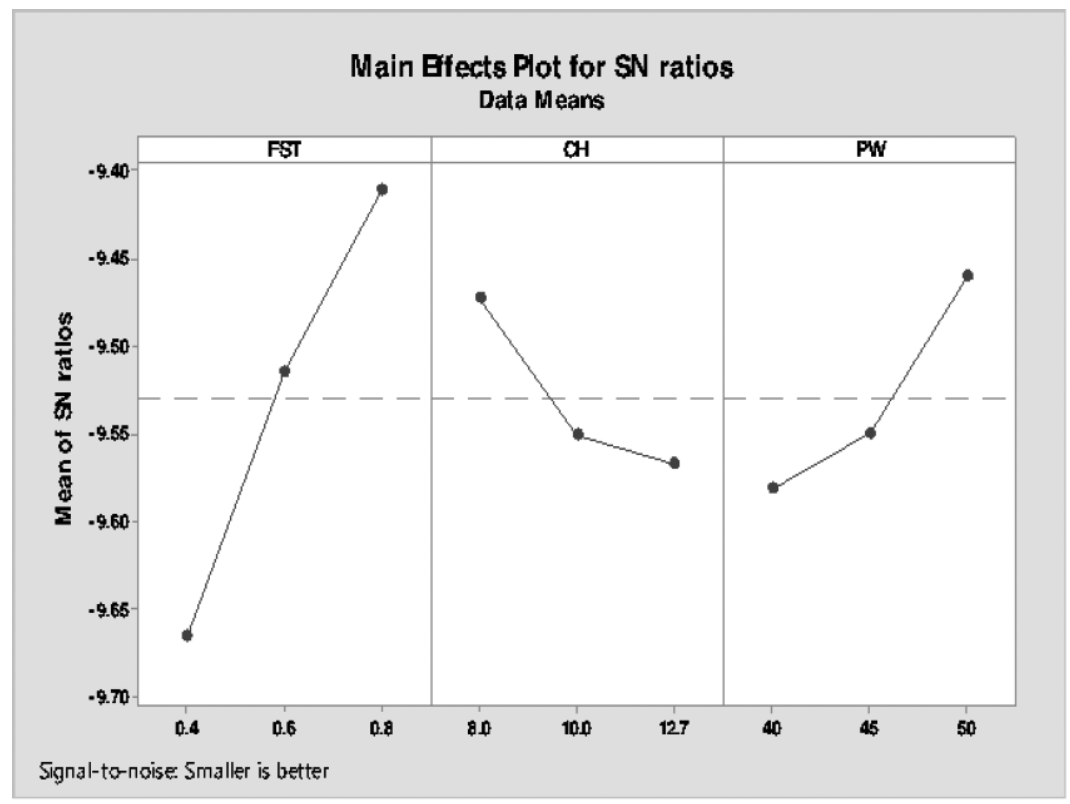

Figure 6. Main effects plot for SN ratios for Shear Stress

From the Taguchi analysis of both the responses, it has been found that the optimum stress values have been achieved for Face sheet Thickness $.8 \mathrm{~mm}$, Honeycomb Core height $8 \mathrm{~mm}$ and Panel Width 50mm

\subsection{Grey Relation Analysis For Validation Of Taguchi Analysis}

Grey relational analysis (GRA) had been invented by a Julong Deng. Grey Relational Analysis (GRA) is a part of Grey System Theory. This analysis can be used as a helpful tool in various engineering and management fields. Ertugrul et al. [14] mentioned that in GRA the correlation between reference sequence and comparability sequences has to be obtained and that correlation can be used to determine the ranking. Hasani et al. [15] observed that the integration of GRA and the Taguchi Method is suitable for the optimization of different process parameters for rotor motor to improve its process efficiency.

Three point bending test is used to find the Sheet Stress and the Shear Stress in the composite sandwich panel. GRA formula for the "Smaller is Better" have been adopted for determining the optimum values for the two different types of stresses.

Table 7. Normalized value, Deviation Sequences and GR Co-efficient for stresses

\begin{tabular}{|c|c|c|c|c|c|c|c|c|}
\hline \multirow{2}{*}{$\begin{array}{l}\text { S. } \\
\text { N. }\end{array}$} & \multirow{2}{*}{$\begin{array}{l}\text { SHEET } \\
\text { STRESS }\end{array}$} & \multirow{2}{*}{$\begin{array}{l}\text { SHEAR } \\
\text { STRESS }\end{array}$} & \multicolumn{2}{|c|}{$\begin{array}{c}\text { NORMALIZED } \\
\text { VALUES }\end{array}$} & \multicolumn{2}{|c|}{$\begin{array}{c}\text { DEVIATION } \\
\text { SEQUENCES }\end{array}$} & \multicolumn{2}{|c|}{$\begin{array}{l}\text { GRER RELATION } \\
\text { CO-EFFICIENT }\end{array}$} \\
\hline & & & $\begin{array}{l}\text { SHEET } \\
\text { STRESS }\end{array}$ & $\begin{array}{l}\text { SHEAR } \\
\text { STRESS } \\
\end{array}$ & $\begin{array}{l}\text { SHEET } \\
\text { STRESS }\end{array}$ & $\begin{array}{l}\text { SHEAR } \\
\text { STRESS }\end{array}$ & $\begin{array}{l}\text { SHEET } \\
\text { STRESS }\end{array}$ & $\begin{array}{l}\text { SHEAR } \\
\text { STRESS } \\
\end{array}$ \\
\hline 1 & 2291.25 & 3.063 & 0 & 0 & 1 & 1 & 0.3333 & 0.3333 \\
\hline 2 & 2286 & 3.053 & 0.0043 & 0.0645 & 0.9956 & 0.9354 & 0.3343 & 0.3483 \\
\hline 3 & 2257.335 & 3.0125 & 0.0280 & 0.3258 & 0.9719 & 0.6741 & 0.3396 & 0.4258 \\
\hline 4 & 1472.625 & 2.959 & 0.6767 & 0.6709 & 0.3232 & 0.3290 & 0.6073 & 0.6031 \\
\hline
\end{tabular}




\begin{tabular}{|c|c|c|c|c|c|c|c|c|}
\hline 5 & 1493.145 & 2.995 & 0.6597 & 0.4387 & 0.3402 & 0.5612 & 0.5950 & 0.4711 \\
\hline 6 & 1505.378 & 3.017 & 0.6496 & 0.2967 & 0.3503 & 0.7032 & 0.5880 & 0.4155 \\
\hline 7 & 1081.605 & 2.908 & 1 & 1 & 0 & 0 & 1 & 1 \\
\hline 8 & 1104.353 & 2.961 & 0.9811 & 0.6580 & 0.0188 & 0.3419 & 0.9637 & 0.5938 \\
\hline 9 & 1119.593 & 2.996 & 0.9685 & 0.4322 & 0.0314 & 0.5677 & 0.9409 & 0.4682 \\
\hline
\end{tabular}

\subsection{Principal Component Analysis For Finding The Weightage Of Two Resposnese, To Be Used To Calculate Grey Relation Grade}

PCA is one of the most widely used multivariate statistical techniques. In this research, the PCA of the Grey Relation Co-efficient has been done using Minitab Software to find the weightage of two responses. The table 8 and table 9 shows the Eigen values and Eigen vectors obtained through Minitab after PCA of two responses.

Table 8. Eigen analysis of the Correlation Matrix

\begin{tabular}{|c|c|c|}
\hline Eigen value & 1.8049 & 0.1951 \\
\hline Proportion & 0.902 & 0.098 \\
\hline Cumulative & 0.902 & 1.000 \\
\hline
\end{tabular}

Table 9. Eigen Vectors

\begin{tabular}{|c|c|c|}
\hline Variable & PC1 & PC2 \\
\hline Sheet Stress & 0.707 & 0.707 \\
\hline Shear Stress & 0.707 & -0.707 \\
\hline
\end{tabular}

The weight of two responses can be calculated by squaring the values under column PC1 of table 9. After squaring the values under PC1 column for two responses it has been observed that the two responses have the equal weightage i.e. $\left(.707^{\wedge} 2=50 \%\right)$.

As the two responses have the equal weight, GRG has been calculated by calculating the average of the Grey Relation Coefficients. Table 10 shows the values of Grey Relation Grades for all 9 configurations of the Taguchi design. Also the Rank has been calculated for the GRG. 
Table 10. Grey Relation Grades and Ranks

\begin{tabular}{|c|c|c|c|c|}
\hline \multirow{2}{*}{ Configuration No. } & \multicolumn{2}{|c|}{ GR Coefficient } & \multirow{2}{*}{ AVERAGE GRG } & \multirow{2}{*}{ RANK } \\
\cline { 2 - 5 } & SHEET STRESS & SHEAR STRESS & & 9 \\
\hline 1 & 0.3333333 & 0.333333333 & 0.333333333 & 8 \\
\hline 2 & 0.3343006 & 0.348314607 & 0.341307605 & 7 \\
\hline 3 & 0.3396825 & 0.425824176 & 0.382753331 & 4 \\
\hline 4 & 0.6073475 & 0.60311284 & 0.605230194 & 5 \\
\hline 5 & 0.5950854 & 0.47112462 & 0.533105017 & 1 \\
\hline 6 & 0.5880084 & 0.415549598 & 0.501778999 & 1 \\
\hline 8 & 1 & 1 & 0.77881139 & 2 \\
\hline 9 & 0.963753 & 0.593869732 & 0.704590973 & 3 \\
\hline
\end{tabular}

\subsection{Determination Of Optimal Input Design Factors and Their Respective Levels-}

To detect out the optimum level of different input factors, the mean value of GRG for each level of input factor has been evaluated and the highest value from the mean of GRG has been selected for each factor.

In Table 11, the bold dark values of GRG represent the largest value for the different levels of each process factor and these bold values correspond to F/S thickness $.8 \mathrm{~mm}$, core height $8 \mathrm{~mm}$ and panel width $50 \mathrm{~mm}$ for optimum response characteristics.

Table 11. Grey Relation Grade Values Analogous to Different Levels of Input Design Factor

\begin{tabular}{|c|c|c|c|}
\hline LEVEL & FST & CH & PW \\
\hline 1 & 0.352464756 & $\mathbf{0 . 6 4 6 1 8 7 8 4 2}$ & 0.537974574 \\
\hline 2 & 0.546704737 & 0.551074671 & 0.550376257 \\
\hline 3 & $\mathbf{0 . 8 2 7 8 0 0 7 8 7}$ & 0.529707767 & $\mathbf{0 . 6 3 8 6 1 9 4 4 9}$ \\
\hline
\end{tabular}

The GRA confirms that the optimum design has is available for F/S thickness .8mm, core height $8 m m$ and panel width $50 \mathrm{~mm}$ for optimum response characteristics

\subsection{Anova Of Input Design Factors On Performance Characteristics}

Kaushik and Singhal [16] observe that, to analyze the contribution of each process factor, Anova can be performed on the GRG values. Table 12, ANOVA analysis of GRG values, depicts the \% contribution of each design factor for the combined response of Sheet Stress and Shear Stress. The table 12 shows that the design factors i.e. Facesheet Thickness, Core Height and Panel Width have $86.33 \%, 5.81 \%$ and $4.53 \%$ contribution respectively and F/S Thickness is the most significant factor. $\mathrm{t}$ 
Table 12. Analysis of Variance of GRG values

\begin{tabular}{|c|c|c|c|c|c|c|c|}
\hline Source & DF & Seq SS & Contribution & Adj. SS & Adj. MS & F-Value & P-Value \\
\hline FST & 2 & 0.34269 & $86.33 \%$ & 0.34269 & 0.171344 & 26.10 & 0.037 \\
\hline CH & 2 & 0.02307 & $5.81 \%$ & 0.02307 & 0.011535 & 1.76 & 0.363 \\
\hline PW & 2 & 0.01807 & $4.55 \%$ & 0.01807 & 0.009035 & 1.38 & 0.421 \\
\hline Error & 2 & 0.01313 & $3.31 \%$ & 0.01313 & 0.006564 & & \\
\hline Total & 8 & 0.39696 & $100.00 \%$ & & & & \\
\hline
\end{tabular}

Regression Equation:

$=0.5757-0.2232$ FST_0 $4-0.0290$ FST_0 $6+0.2521$ FST_0 $8+0.0705$ CH_8 0

-0.0246 CH_10.0 - 0.0459 CH_12.7 - 0.0377 PW_40 - 0.0253 PW_45 + 0.0630 PW_50

\subsection{Confirmatory Test}

The Table13 shown below explains that the results of GRA analysis are in total agreement with the results of the Taguchi Analysis. Also it has been observed that the optimum values for two types of Stresses for exists at F/S Thickness of $.8 \mathrm{~mm}$, Core height of $8 \mathrm{~mm}$ and Sandwich Width of $50 \mathrm{~mm}$.

Table 15. Analysis of results of Taguchi and GR Analysis

\begin{tabular}{|c|c|c|c|}
\hline $\begin{array}{c}\text { INPUT } \\
\text { FACTORS }\end{array}$ & $\begin{array}{c}\text { TAGUCHI OPTIMAL } \\
\text { VALUES }\end{array}$ & $\begin{array}{c}\text { GRA OPTIMAL } \\
\text { VALUES }\end{array}$ & LEVEL \\
\hline FS Thickness & 3 & 3 & $3(.8 \mathrm{~mm})$ \\
\hline HC Height & 1 & 1 & $1(8 \mathrm{~mm}$ \\
\hline Panel Width & 3 & 3 & $3(50 \mathrm{~mm})$ \\
\hline
\end{tabular}

\section{CONCLUSION}

In this research, three main design factors i.e. facesheet thickness, core height and panel with each having three different values (levels) have been chosen and a L9 Orthogonal Array has been generated using Taguchi Design in Minitab software. The Sheet Stresses and Shear Stresses have been calculated for all 9 configurations. From Taguchi Analysis it has been observed that the optimum level for facesheet thickness is .8mm, for core height is $8 \mathrm{~mm}$ and for panel width is $50 \mathrm{~mm}$. Then PCA assisted GRA has been performed on the two responses and it has been observed that the optimum parameter levels are similar to that of Taguchi Analysis. i.e. facesheet thickness $.8 \mathrm{~mm}$, core height $8 \mathrm{~mm}$ and panel width $50 \mathrm{~mm}$. ANOVA analysis has also been carried out to find out the effect of different design parameters on the different stress values of the sandwich panel. It has been observed that the Facesheet thickness has the maximum effect on stress properties.

It has been observed that the optimum stress properties for the sandwich panel exists at Face sheet Thickness $.8 \mathrm{~mm}$, Core height $8 \mathrm{~mm}$ and Panel width 50mm and the values of Sheet Stress and Shear Stress are $1081.605 \mathrm{~N} / \mathrm{mm} 2$ 
and $2.908 \mathrm{~N} / \mathrm{mm} 2$ for this configuration. The ANOVA analysis shows that the Design factor Facesheet Thickness, Core Height and Panel Width have $86.33 \%, 5.81 \%$ and $4.53 \%$ contribution respectively and the most significant factor, affecting the sandwich stress properties is facesheet thickness.

\section{REFERENCES}

Gibson, J., Ashby, F. 2001. Cellular Solids: Structure and Properties. Cambridge University Press.

www.plascore.com/download/datasheets/honeycomb_data_sheets/PLA_PK2_2019.pdf.

Kumar, J.S. and Kalaichelvan, K. 2018. Multi-response Optimization on Structural Parameters of Honeycomb Core Sandwich Structure for Low Velocity Impact Test. Silicon. 10: 879-889.

Rupani, S. V., Shivang, S. J., Acharya, D. G. 2017. Design, Modelling and Manufacturing aspects of Honeycomb Sandwich Structures. International Journal of Scientific Development and Research. 2(4):526.532.

Okan, C., Merve, E., Altan, K. 2017. Accurate Equivalent Models of Sandwich Laminates with Honeycomb Core and Composite Face Sheets via Optimization Involving Modal Behavior. Journal of Sandwich Structures \& Materials. 19(2):139-166, doi:10.1177/1099636215613934.

Kumar, A., Angra, S., Chanda, A. K. 2020. Analysis of the effects of varying core thicknesses of Kevlar Honeycomb sandwich structures under different regimes of testing. Materials Today: Proceedings. 21:1615-1623. doi.10.1016/j.matpr.2019.11.242

Prakash, M., Jagannatha, V.L., Sharma, R. , Mohan, B. 2012.Influence of Cell Size on the Core Shear Properties of FRP Honeycomb Sandwich Panels. Materials and Manufacturing Processes. 27. 169-176. doi.10.1080/10426914.2011.560227.

Sawal, N., Basit A., Mohd, N., Akil, H. Md. 2015.Effect of Cell Size Material on the Mechanical Properties of Honeycomb Core Structure. International Journal of Science and Research. 4(2): 80-84.

Thomas, T., Tiwari G. 2019. Crushing behavior of honeycomb structure: a review. International Journal of Crash worthiness. DOI:10.1080/13588265.2018.1480471.

Rao, K.K., Rao, K.J., Sarwade, A.G., SarathChandra, M. 2012.International Journal of Engineering Research and Applications. 2(3):365-374.

Akiwate, S.B., Shinde, V.D. 2017.Experimental Investigation of Bending behaviour of Aluminum Alloy Honey comb Sandwich Structure using Four Point Bending Tests. International Journal for Innovative Research in Science \& Technologyl.4(1):97-101.

Kumar, A., Chanda, A. K., Angra, S. 2021. Analysis of effects of varying face sheet thickness on different properties of composite sandwich Structure. Materials Today: Proceedings. 38 (1):116-121. doi.10.1016/j.matpr.2020.06.114.

Mohammed, D.F., Ameen, H.A, Mashloosh,K.M. 2016. Experimental and Numerical Study of Bending Behavior for Honeycomb Sandwich Panel with Different Core Configurations. The Iraqi Journal For Mechanical And Material Engineering, 16(4):315-328.

Ertugrul, I., Oztas, T., Ozcil, A., \& Oztas, G.Z. 2016. Grey Relational Analysis Approach in Academic Performance Comparison Of University: A Case Study Of Turkish Universities.European Scientific Journal.12 (10). doi.10.19044/esj.2016.v12n10p\%p. 
Hossein,H., Somayeh, T., Ghafour, A. 2012.Grey Relational Analysis to Determine the Optimum Process Parameters for Open-End Spinning Yarns. Journal of engineered fibers and fabrics. 7:81-86. doi.10.1177/155892501200700212.

Kaushik, N., Singhal, S. 2018.Optimization of Wear Properties in Aluminum Metal Matrix Composites using Hybrid Taguchi-GRA-PCA. International Journal of Performability Engineering, 14(5):857-870.doi 10.23940/ijpe.18.05.p4.857870. 